This item was submitted to Loughborough's Research Repository by the author.

Items in Figshare are protected by copyright, with all rights reserved, unless otherwise indicated.

\title{
Evaluation of factors and approaches affecting emergency department space planning
}

PLEASE CITE THE PUBLISHED VERSION

http://dx.doi.org/10.1108/F-09-2012-0073

\section{PUBLISHER}

(C) Emerald Group Publishing Limited

\section{VERSION}

AM (Accepted Manuscript)

\section{PUBLISHER STATEMENT}

This work is made available according to the conditions of the Creative Commons Attribution-NonCommercialNoDerivatives 4.0 International (CC BY-NC-ND 4.0) licence. Full details of this licence are available at: https://creativecommons.org/licenses/by-nc-nd/4.0/

\section{LICENCE}

CC BY-NC-ND 4.0

\section{REPOSITORY RECORD}

Pascale, Federica, Nebil Achour, Andrew D.F. Price, and Francesco Polverino. 2019. "Evaluation of Factors and Approaches Affecting Emergency Department Space Planning". figshare.

https://hdl.handle.net/2134/16165. 


\title{
Evaluation of factors and approaches affecting emergency department space planning
}

\author{
Pascale, $\mathrm{F}^{1}$, Achour, $\mathrm{N}^{1}$, Price, A.D. $\mathrm{F}^{1}$ and Polverino, $\mathrm{F}^{2}$ \\ ${ }^{1}$ School of Civil and Building Engineering, Loughborough University, UK \\ ${ }^{2}$ University of Naples Federico II, Italy
}

\begin{abstract}
:
Purpose - This paper aims to evaluate emergency department (ED) design space planning approaches and draw lessons for developing more resilient and integrated ED guidelines. Two key objectives have been set; these include: exploring potential factors affecting the ED performance, and investigate how ED space planning is addressed internationally through the evaluation of international case studies and design guidelines.

Design/methodology/approach - A robust research method has been adopted including comprehensive literature review in addition to 76 case studies from Italy and the USA.

Findings - Findings show that the important factors in defining ED space requirements are attendance variability, vulnerable groups and mass casualty events. The study concludes that current design guidelines and approaches need to be updated to meet with the current and future demand by taking into account design performance: effectiveness, efficiency and resilience, to avoid underestimating ED space; and that the US EDs are in a better position, than Italian EDs, to increase capacity when needed.

Originality/value - The contribution of this study is in providing a tangible "understanding" of factors influencing ED design and prepares a firm ground to develop more resilient and integrated design guidelines, able to meet current, exceptional and long-term needs of EDs. The study also shows that research can provide a valuable contribution to improve ED design which needs to feed more in practice to improve design process and guidelines.
\end{abstract}

\section{Introduction}

With the ever increasing number of hazards, "emergency departments, as principal portals of entry into crowded health care systems, are increasingly faced with the challenge of ensuring patients have access to care during periods when demand exceeds available resources. This challenge is magnified when mass casualty incidents or epidemics occur” (ACEP, 2011). Vulnerable people are an additional complication to surge demand as they require planning to take into account their special needs during emergency situations, because "public health emergencies and pandemics are not equal opportunity offenders” (IOM, 2010).

Despite the fact that emergency departments (EDs) "play a critical role in disaster preparedness" (Hayward, 2006), concerns have been expressed on the ability of many EDs, operating at or near full capacity and severely crowded, to cope with sudden increases in demand in case of mass casualties (CFEC, 2007, Schneider et al., 2003). In some countries, overcrowding is the prime factor affecting and compromising the quality and the timeliness of service (Fatovich, 2002). This is due to the increasing demand in using urgent and emergency facilities. For example, in England from 2010 to 2011 there were over 16 million attendance at the different emergency and urgent care services (HSCIC, 2012b). In the United States (US) visits to EDs increased by 23 per cent between 1997 and 2007 (Niska et al., 2010) to reach 124 million visits in 2008 (Niska and Shimizu, 2011). In Italy, with a population of approximately 60 million, nearly one in two people access EDs every year 
(Adnkronos Salute, 2011). Moreover, a disproportionate number of ED visits are caused by a small subgroup of ED patients, who are defined as frequent users, and identified as vulnerable patients (Althaus et al., 2011). In several studies, ED use has been casually linked to demographics: aspects, health status, and health care access. In addition, there are contributory socio-economic factors, such as poverty, advanced age, homelessness, and minority race (Sun et al., 2003).

Considerable research is on-going regarding the development of new pathways and processes to reduce the high cost associated with the large number of ED visits. Potentially, this will reduce the number of day-to-day ED visits but will not increase the resilience and the social aspects of these critical facilities, especially in regard to the entire life cycle of an ED. Specifically, "ED clinicians reported that the size of the ED was often not large enough to meet the needs of patients presenting for care" (Magid et al., 2009). EDs are therefore required to be more resilient to cope with challenges resulting from the changing patient patterns, and unexpected situations resulting from major emergencies often associated with natural or technological hazards.

The aim of this research paper is to evaluate ED design space planning approaches and draw lessons for developing more resilient and integrated ED guidelines. Two key objectives have been set; these include: (1) exploring potential factors affecting ED performance, (2) and investigate how ED space planning is addressed internationally through the evaluation of international case studies and design guidelines.

\section{Methodology}

This study adopted a mixed research methodology, defined as "the class of research where the researcher mixes or combines quantitative and qualitative research techniques, methods, approaches, concepts or language into a single study" (Johnson and Anthony, 2004), "for generating important research questions and providing warranted answers to those questions" (Johnson et al., 2007). This method offers a more comprehensive approach to addressing a complex problem such as ED space planning.

\section{Data collection}

A comprehensive literature review was conducted to gather information about current ED issues, performance and design approach, including research articles, reports, governmental and non-governmental guidelines. Guidance from the US, the United Kingdom (UK), Australia and Italy for designing EDs were analysed thoroughly and complemented by unstructured interviews with architects, healthcare managers and ED staff. In addition, there was a careful collection of information, related to annual attendance and EDs total floor area, from 76 ED case studies (55 from the US and 21 from Italy), provided by hospitals and architects in order to complement the information gathered from guidelines within the real situation of existing EDs. One of the main objects was to obtain a sample clearly representative of the ED situation in these two countries. Data has been chosen to cover a wide range of territory: 27 of the 50 States of the US are represented in the sample, whilst the Italian case studies were from the North, the Centre and the South of the country. 
In addition, the study population is representative of different types of cities. Most of the EDs are based in medium sized cities of between 10,000 and 100,000 inhabitants. Nearly $50 \%$ of the US case studies are in cities with a density of between 1000 and 2000 people per square metre $\left(\mathrm{prs} / \mathrm{km}^{2}\right)$, whilst the majority of Italian case studies are in cities where the density is more than $2000\left(\mathrm{prs} / \mathrm{km}^{2}\right)$. Both samples cover similar rates of vulnerable [age] groups: case studies cover approximately $40 \%$ of junior (prs $<18$ ) and senior (prs $>65$ ) population and thus indicate the importance of these samples. Data collection was conducted from July to September 2011. The choice of the US and Italy was based on the fact that they provide a good representation of countries where ED space planning is based on innovative operation management theories and they are countries which still rely on out-dated strategies. In order to study the characteristics of ED locations further, analysis was conducted relating to the demographic and the risk context. Demographic information was sought from the US Census and the Italian National Institute of Statistics (ISTAT) and risk related information was collected from different databases and agencies, such as The International Disaster Database (EM-DAT), the Federal Emergency Management Agency (FEMA), and the Italian Civil Protection.

\section{Data analysis}

The chosen criteria to assess the performance of these EDs has been to evaluate the trend of the space planning in relation to different parameters identified from the literature review as relevant for ED performance by using regression analysis. The space provision of EDs has been assessed by analysing the relationship between: (1) the average of the annual attendance and EDs total floor area; (2) the relationship between the total area and the city population; ; (3) the relationship between the total area and the social factors identified above, namely aging population and deprived population. It was not possible to make the same analysis considering children because, in Italy, children are treated in a paediatric ED. Data was plotted on two graphs; the first graph showing the variation of the total area of EDs against annual access, for both guidelines and real case studies (Figure 2). The next three graphs illustrate the variation of the total area against the city population; aging population; and deprived population (Figures 3, 4, 5). The factors presented on the abscissas of these last three graphs were transformed into a logarithmic scale after having divided it by the number of EDs in the cities (see Table 1), in order to assess of the effects on a single ED. In addition, a linear regression was made to understand the trend.

Table 1: Analysis rate for space performance for EDs attendance

\begin{tabular}{cc}
\hline Factor & Rate \\
\hline City population & $E D_{-} P O P=\log _{10}\left[\frac{\text { Pop }}{E D_{s}}\right]$ \\
Aging population & $E D_{-} A P O P=\log _{10}\left[\frac{\text { Aging Pop }}{E D_{s}}\right]$ \\
Deprived population & $E D_{-} D P O P=\log _{10}\left[\frac{\text { Deprived Pop }}{E D_{s}}\right]$ \\
\hline
\end{tabular}




\section{Factors affecting space planning}

\section{ED attendance variability}

The international crisis of ED overcrowding (Hoot, 2008) sharply affects the US and Europe (Exadaktylos et al., 2008). The American College of Emergency Physicians (ACEP, 2006) states that "crowding occurs when the identified need for emergency services exceeds available resources for patient care in the emergency department, hospital, or both”. This phenomenon has several negative effects on ED efficiency, which can be grouped in: increasing adverse outcomes, reducing quality, impairing access, and causing provider losses (Hoot, 2008). Because of overcrowding "ED providers often face limitations on the amount of space available in which to provide care” (CFEC, 2007) and this needs to be considered during the design process. Fluctuation of daily patient volumes (Jones et al., 2008) and variation in demand (variation in arrival patterns, patient mix treatment strategies) (Zilm et al., 2010) are crucial parameters to evaluate the impact of overcrowding on the space ratios. This is because they allow the taking into account of the variability of attendance in the design process. A valuable support for addressing issues related to the attendance variability can be provided by operational methods. Researches have been developed to apply these methods in ED planning, including strategies for estimating treatment bed needs in ED proposed by Zilm (2004), or use of Lean techniques suggested by Crane and Noon (2011), or quality improvement programmes recommended by Welch and Park (2009).

Unfortunately, there are still countries where "capacity planning is normally based on averages" (Exadaktylos et al., 2008), In addition, “most emergency department workload data includes total visits per month or year from which average daily can be calculated" (Hayward, 2006). Calculations utilising workload average do not necessarily meet ED attendance variability and the peak in demand, and therefore, will lead to an underestimated space requirement (Hayward, 2006); whilst detailed peak period study would provide a more accurate and comprehensive picture for space planning (Zilm, 2004).

\section{Vulnerable groups and health need}

With the current trend of social and environmental change and the increase of vulnerable groups (Arkun et al., 2010), the design of an ED needs to take into consideration the effect these changes will have on society and health. "Vulnerable populations are subgroups of the general population who are at greater risk of developing a wider range of social and health problems than the population as a whole" (Van Zandt et al., 2008). The definition of vulnerable people can vary between different countries (SEPHO, 2010); however, the most important characteristics of definition are age, sex, ethnicity and location. Literature suggests that deprived people are also a component of vulnerable groups and that children, elderly and deprived people are some of most crucial factors affecting EDs (see Table 1).

Elderly people: The growing aging population increases the concerns related to overcrowding because this group presents complex health care needs, using proportionally more ED services than any other age groups (Gruneir et al., 2011). In 2008, the US statistics demonstrated that in every 100 visits 62 were people aged 75 years and over (Niska and 
Shimizu, 2011); whilst in Italy they represent the 50-60\% of the total visits in EDs (Palleschi et al., 2003). Consequently, an aging population needs to have a priority role in functionality and space planning of EDs (Huddy, 2002).

Children: In the US in 2007 "about one-fifth of ED visits by children younger than 15 years of age were to paediatric EDs. There were 121 ED visits for asthma per 10,000 children under 5 years of age” (Niska et al., 2010). In England, in the period 2009-11, the population under 19 years old represented 28\% of patients attending EDs (HSCIC, 2012a).

Deprived people: Demographic predictors, such as poverty and low education, entail frequent use of ED facilities (Sun et al., 2003, Bianco et al., 2003). "In the United States, as the numbers of uninsured patients increase, EDs close; as it becomes more difficult for uninsured patients to access primary care, an increasing number of uninsured patients present to EDs" (Newton et al., 2008). It emerged from interviews that Italian EDs are heavily affected by the increase of illegal immigrants, especially pregnant women and children, because these facilities are the only provider of care illegal immigrants can access.

"Vulnerable populations such as those with poor health, disabilities, and chronic diseases are at an increased risk of adverse health outcomes resulting from natural disasters” (Bethel et al., 2011). Recent earthquakes, such as those in China (2008) and Haiti (2010) have involved paediatric victims, emphasising the need for paediatric disaster preparedness (Burke et al., 2010). "Distinctive physiological, developmental, and psychological attributes of children make them one of the most challenging populations to treat during mass casualty incidents” (Burke et al., 2010). The 2011 Tōhoku Earthquake and Tsunami (Japan) had a devastating impact on the ageing population, with dozens of elderly people dead in hospitals and residential homes (Booth and McCurryo, 2011). Older adults "are more likely to have higher morbidity and mortality rates than the rest of the population in a disaster" (Tuohy and Stephens, 2012), because of reduced physical mobility, and diminished sensory awareness, chronic health conditions, and social and psychological impairment (Fernandez et al., 2002).

\section{Mass casualty events needs}

The increasing number of risks has emphasised the need for resilient healthcare facilities capable of accommodating and dealing with potential mass casualties. EDs have a crucial role to play in disaster prevention and management (Hayward, 2006), "because they are the link between out-of-hospital and hospital resources” (McCarthy et al., 2006) and frequently the first destination of most injuries (Halpern et al., 2003). EDs are required to deal with potentially large numbers of patients (Stratton and Tyler, 2006). As such, they are expected to be sufficiently resilient to continue providing healthcare during the disaster and be able to expand their capacity to receive larger numbers than those they receive on a day-to-day basis.

Analysing the potential disasters and the effect they can have on individuals and infrastructures can help to develop a new design approach. Monitoring of natural and manmade disasters in the past 10 years indicates that an ED needs to be designed to cope with a four-fold surge demand, but just a few of them can do it (Zilm, 2007). An increase in complexity of a Mass Casualty Event (MCE) management is caused by specific vulnerable 
Pascale, F, Achour, N, Price, A D F and Polverino, F (2014), Evaluation of factors and approaches affecting emergency department space planning, Facilities, 32(13/14), 761-785. DOI: http://dx.doi.org/10.1108/F-09$\underline{2012-0073}$

groups, such as children and the elderly, which presents particular challenges in instances of disaster (Burke et al., 2010, IOM, 2010).

Table 2: Factors affecting the use of EDs according to vulnerable groups

\begin{tabular}{lll}
\hline Groups & \multicolumn{1}{c}{$\begin{array}{c}\text { Factors affecting the use of Emergency } \\
\text { Departments }\end{array}$} & Source of information \\
\hline $\begin{array}{l}\text { Deprived } \\
\text { people }\end{array}$ & $\begin{array}{l}\text { Deprivation and poverty; loneliness; capacity to understand } \\
\text { health-related materials; uninsured patients; return visits }\end{array}$ & $\begin{array}{l}\text { (Cooke et al., 2004) (Newton et } \\
\text { al., 2008) (Sun et al., 2003) } \\
\text { (Malone, 1995) }\end{array}$ \\
\hline Elderly & $\begin{array}{l}\text { Ageing; loneliness; lack of a regular physician for the } \\
\text { (lderly; return visits; capacity to understand health-related } \\
\text { (Cooke et al., 2004) (Dove and } \\
\text { materials; influenza-associated respiratory disease among } \\
\text { adults over 65 years; injuries due to falls and self-care } \\
\text { problems; old-old patients. }\end{array}$ & $\begin{array}{l}\text { (Aminzadeh and Dalziel, 2002) } \\
\text { (Gruneir et al., 2011) (Carmel et } \\
\text { al., 1990) }\end{array}$ \\
\hline Children & $\begin{array}{l}\text { Warm weather associated with incidence of paediatric } \\
\text { injuries; convenience for parents; influenza-associated } \\
\text { respiratory disease; uninsured children; asthma; }\end{array}$ & $\begin{array}{l}\text { (Cooke et al., 2004) } \\
\text { Othen) (Galbraith. }\end{array}$ \\
\hline Others & $\begin{array}{l}\text { Distance from the emergency department; particular } \\
\text { gaseous and particulate pollutants; thunderstorms } \\
\text { exacerbating the incidence of asthma; non-compliance with } \\
\text { prescribed drug treatment; Ramadan. }\end{array}$ & $\begin{array}{l}\text { (Cooke et al., 2004) } \\
\text { (Sills et al., 2011) }\end{array}$ \\
\hline
\end{tabular}

\section{Evaluation of design guidelines}

\section{Space planning for ED attendance}

Despite the fact that EDs "are a vital component in our health care safety net, available 24 hours a day, 7 days a week, for all who require care” (CPEM, 2004), many countries have yet to develop or improve their design guidelines. For example, Italian guidelines (SIMEU, 2005) are unable to meet the current needs of EDs because of: (1) the lack of indicators to define the minimum required total floor area; and (2) the design model links dimensional specifications to a fixed number of accessions (25,000 patients per year), which is less than the current volume experienced in ED. Conversely, countries such as the US, the UK and Australia have developed more articulated and advanced guidelines such as shown in Table 3. However, this guidance, even when accurate, defines ED size based on the average of annual attendance and fails to consider attendance variability in EDs, as it is possible to observe in the last column of Table 2 'Total Area', which illustrates the variability of total area (TA) to the annual attendance (AA). Research outputs, such as Zilm (2004), Crane and Noon (2011) and Welch and Park (2009), propose new methods based on operational approaches (e.g. Lean) that could support the improvement of these guidelines. Even though in countries such as the UK, where the Health Building Notes (HBN22) guidance (DH, 2005) were developed based on Lean principles, space planning is still based on the average of annual attendance. 
Pascale, F, Achour, N, Price, A D F and Polverino, F (2014), Evaluation of factors and approaches affecting emergency department space planning, Facilities, 32(13/14), 761-785. DOI: http://dx.doi.org/10.1108/F-09$\underline{2012-0073}$

Table 3: International EDs Guidelines

\begin{tabular}{llllll}
\hline Guidelines & Publisher & Country & Year & $\begin{array}{l}\text { Patients } \\
\text { evaluation } \\
\text { method }\end{array}$ & $\begin{array}{l}\text { Annual Attendance } \\
\text { range (AA) } \\
\text { (people) }\end{array}$
\end{tabular}

\begin{tabular}{|c|c|c|c|c|c|c|}
\hline $\begin{array}{l}\text { Emergency } \\
\text { Department Design: A } \\
\text { Practical Guide to } \\
\text { Planning for the } \\
\text { Future }\end{array}$ & $\begin{array}{l}\text { American } \\
\text { College of } \\
\text { Emergency } \\
\text { Physicians } \\
\text { (ACEP) }\end{array}$ & US & 2002 & $\begin{array}{l}\text { Triage and } \\
\text { Fast-Track }\end{array}$ & $10,000-150,000$ & $\mathrm{TA}=0.0397(\mathrm{AA})+712.72$ \\
\hline $\begin{array}{l}\text { HBN } 22 \text { Accident and } \\
\text { emergency facilities } \\
\text { for adults and } \\
\text { children }\end{array}$ & $\begin{array}{l}\text { Department of } \\
\text { Health (DH) }\end{array}$ & UK & 2005 & $\begin{array}{l}\text { See and } \\
\text { Treat }\end{array}$ & $40,000-90,000$ & $\mathrm{TA}=772.37 \ln (\mathrm{AA})-6894.8$ \\
\hline $\begin{array}{l}\text { Guidelines on } \\
\text { Emergency } \\
\text { Department Design }\end{array}$ & $\begin{array}{l}\text { Australian } \\
\text { College for } \\
\text { Emergency } \\
\text { Medicine } \\
\text { (ACEM) }\end{array}$ & Australia & 2007 & $\begin{array}{l}\text { Triage and } \\
\text { Fast-Track }\end{array}$ & $(-)$ & $\begin{array}{l}\mathrm{TA}=\left(50 \mathrm{~m}^{2} / 1000\right)^{* A A} \\
\mathrm{TA}>700 \mathrm{~m}^{2}\end{array}$ \\
\hline $\begin{array}{l}\text { Structural, } \\
\text { technological, } \\
\text { organizational and } \\
\text { staff standard for } \\
\text { Emergency } \\
\text { Departments }\end{array}$ & $\begin{array}{l}\text { Italian Society } \\
\text { for } \\
\text { Emergency- } \\
\text { Urgency } \\
\text { Medicine } \\
\text { (SIMEU) }\end{array}$ & Italy & 2005 & Triage & 25,000 & $(-)$ \\
\hline
\end{tabular}

The American College of Emergency Physicians (ACEP) guidelines take into account additional parameters to define the space requirements (Huddy, 2002). These include length of stay, location of observation and evaluation unit in or out of ED; time of admission to hospital; average turnaround times for results from laboratories; the percentage of patients admitted to hospital and the percentage of emergency, urgent, and non-urgent attendances. These parameters, however, are mostly related to hospital capacity, and demand characteristics are considered only in terms of percentage. The Australian College for Emergency Medicine (ACEM, 2007) states that additional information, such as annual census and trends and average daily census with peak patient volumes, should assist the ED space planning, but no indications are provided about how to take into account these parameters in the space planning. There is a need therefore to improve the current guidelines to cope with peaks due to daily and monthly demand variations. To compare the space requirements provided by these guidelines, the data related to the different approaches were graphed in order to have the same number of data for each of them in an interval between 10,000 and 150,000 attendances per year (Figure 1). 


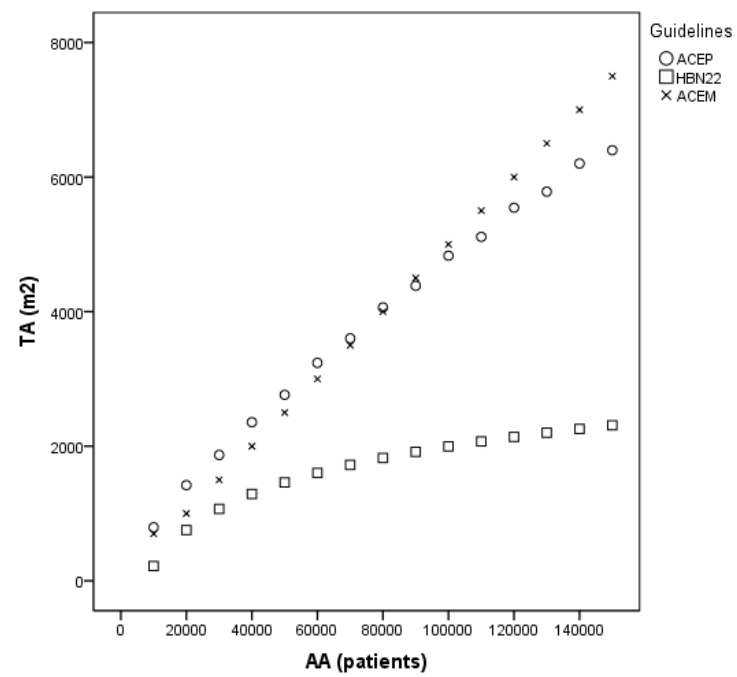

Figure 1: Total area trend on the annual accesses for ACEP, HBN22 and ACEM guidelines.

As the scatter plot shows, whilst EDs floor area for the ACEP and the ACEM guidelines increase linearly on the annual attendance, the data from the HBN22 follow a logarithmic trend. The different trends entail a significant gap between the UK guidelines on the one side and the US and Australian ones on the other. Considering the mean values of the total area provided by the ACEP and ACEM guidelines, they are twice as large as the HBN22; however, when considering the maximum value, they become three times larger than the HBN22. The ED configuration proposed by ACEP and HBN22 has individual patient rooms, whilst ACEM suggests open-bay care areas for the acute treatment area. Since private rooms require more net square metres and circulation than open bay configurations, it is expected to have smaller EDs designed according to ACEM than HBN22. This gap can be explained by three reasons: (1) ACEP and ACEM service models are based on Triage whilst the HBN22 is based on the See and Treat, which follows Lean principles (Jones et al., 2006); (2) ACEP and ACEM allocate Fast-Track area for less urgent patients, whilst in the UK these patients are treated in streaming areas; and (3) ACEP considers the digital imaging suite as part of ED, whilst the HBN22 considers it as an external service.

In summary, ED design guidelines are very complex and involve many factors, yet ED attendance is limited to average numbers despite the variability.

\section{Space planning for vulnerable groups}

Many guidelines recognise the effect vulnerable groups have on EDs and have taken measures to address this need. For example, the ACEP and ACEM guidelines recognise that special consideration should be taken for the ageing and paediatric populations, whilst the HBN22 emphasises that "planning teams should consider the provision of a separate children's area for all departments with an attendance of over 70,000 per year” (DH, 2005). These guidelines limit vulnerable groups to senior people and children without a clear explanation of the reason for this. Such explanation will support the planning and the development of models to estimate the needs of these groups and design accordingly. The US Centre for Disease Control and Prevention (CDC) has developed a method to estimate the 
demand for these special cohorts which could be a good start for integration into relevant guidelines, raising awareness of this important factor and influencing practice.

\section{Space planning for mass casualty events}

Huddy (1996) recognised the absence of surge capacity, as one of the 25 problems to avoid in ED planning. He affirms that "no ED can be designed large enough for an unlimited surge in patient volume. However, EDs must identify and plan for surge capacity in a way that allows the architecture to support these unexpected volume surges".

'Project ER One' (Smith et al., 2003) is one of the few initiatives to increase capacity in the case of a major disaster. The Project was developed by a number of multi-disciplinary research teams with the objectives to: (1) provide "insight into what should be considered regarding the design of emergency facilities to respond to 'surge' and high-risk events" (Zilm, 2007); and (2) improve the performance of EDs in special circumstances in three main areas: threat mitigation; medical consequence management; scalability. The recommendations developed by the Project ER One were used for planning and designing the new ED at the Tampa General Hospital in Florida (Zilm, 2008). The facility was designed to: (1) double the ordinary capacity of the treatment area (2) use support space for patient care (3) have appropriate space to manage epidemic situations (4) have mass-decontamination capabilities for chemical or toxic events (Berry, 2009).

Despite the fact that "the Project ER One design was accomplished several years ago and many of the design features are no longer considered up-to-date" (Zilm et al., 2008), some of the concepts and the design features are still valid, but unfortunately, they are not yet part of international EDs guidelines. Zilm (2007) recognises the unfeasibility of implimenting the Project ER One design concepts in the US key emergency facilities because of the lack of funding. This is even more valid in Europe, where public involvement in the healthcare sector makes the possibility of large investment more challenging. However, parts of the design concepts followed in the Project ER One are able to improve resilience and costeffectiveness. These concepts include: definition of the facility mission and role in normal and contingency operations; risk and vulnerability analysis; definition of constraints; and use of modelling and simulation to test different design solutions.

The guidance published by the World Health Organization (2007) Mass Casualty Management Systems: Strategies and Guidelines for health sector capacity building suggests that one of the main factors to deal with MCE is the capacity and planning each healthcare facility has to arrange for these events. "In most cases, however, this involves the development of disaster plans after the hospital has been designed, which often equates to which car park will host certain functions such as triage, casualty reception, and decontamination" (Smith et al., 2003). For example, the HBN22 states that "planners should identify any design implications that need to be addressed in receiving large numbers of people in the event of a major incident" (DH, 2005). Moreover, it provides very generic indications about design issues associated with a major incident, such as the use of identification of possible adjacent departments and parking areas, provision of storage space for equipment and supplies and possible ED reconfiguration (DH, 2005). These design 
features appear to be hypothetical rather than a concrete reality. ACEM recognises EDs must plan for accommodating disaster patients as part of any regional disaster plan.

In this case, the requirements provided to improve ED resilience are only focused on the response to chemical, biological and radiation incidents. In Italy, the role of ED in the management of MCE has started to be recognised; SIMEU (2007) states that ED must be equipped with an area for decontamination and for MCE. The guidelines do not set any requirement for this area as they refer merely to areas equipped with numerous outlets for medical gases and vacuum suction. A solution of this type is not recommended because such empty areas are not planned to be used in daily activities which leads to non-cost-effective solutions (Smith et al., 2003).

\section{Performance of the Emergency Departments}

\section{Space performance for ED attendance}

Figure 2 illustrates that for both countries the relationship between the total area of EDs and annual attendance has a rising trend. The US regression line presents a steeper slope; on average the US EDs are twice as large as the Italian EDs. Moreover, the size of the US EDs is very close to the one proposed by the US and Australian guidelines, whilst the Italian ones are far lower than these two guidelines and closer to the UK guidance. In-depth observation of the graph demonstrates that the US 80,000 patient-per-year capacity EDs are slightly larger than what is advised by the ACEM and ACEP guidelines; whilst, EDs designed for more than 80,000 patients per year present a size included between the US and the Australian guidelines. Italian case studies converge with the US and Australian cases for small EDs but diverge for larger ones to get much closer to the UK guidelines. The second graph (Figure 4), illustrating the variation of the total area against the city population, generally presents an increasing trend. However, analysing this data, through the linear regression, indicates a difference between the US and the Italian case studies. Whilst the size of the US EDs increases with the rise of potential patient numbers, the Italian ones decrease. This indicates that the Italian approach could be based on management, such as the UK case, or lack of clear design process for design guidelines. However, considering that Italian emergency care is based on Triage (see Table 2), which does not necessarily follow operational approaches (e.g. Lean principles, Queue theory) it is more likely that there is a lack of clear design process and that Italian case studies fall in the category of under-estimated floor area. 


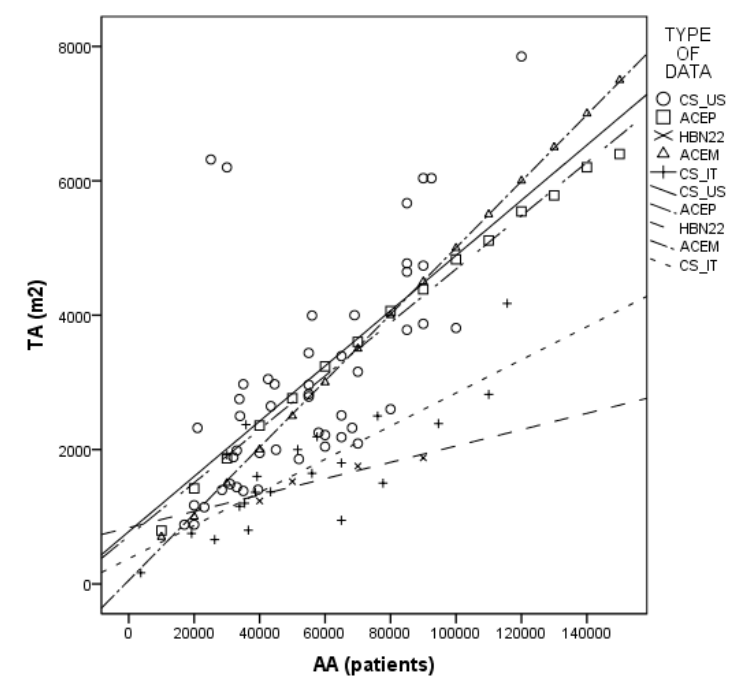

Figure 2: Annual attendance against EDs floor area

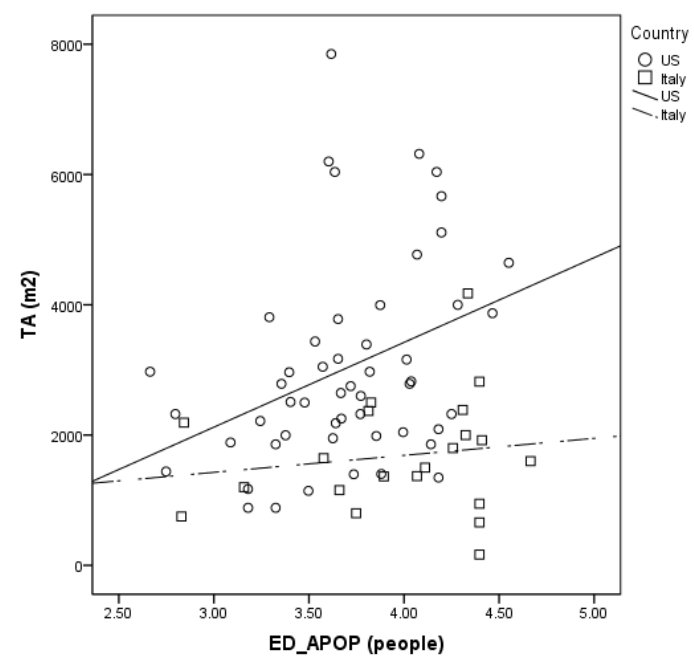

Figure 4: Aging population against EDs floor area

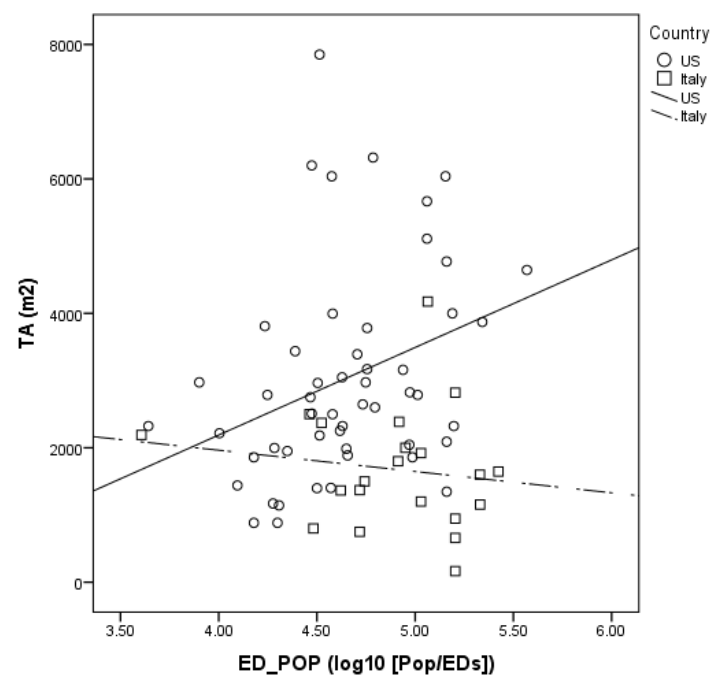

Figure 3: City population against EDs floor area

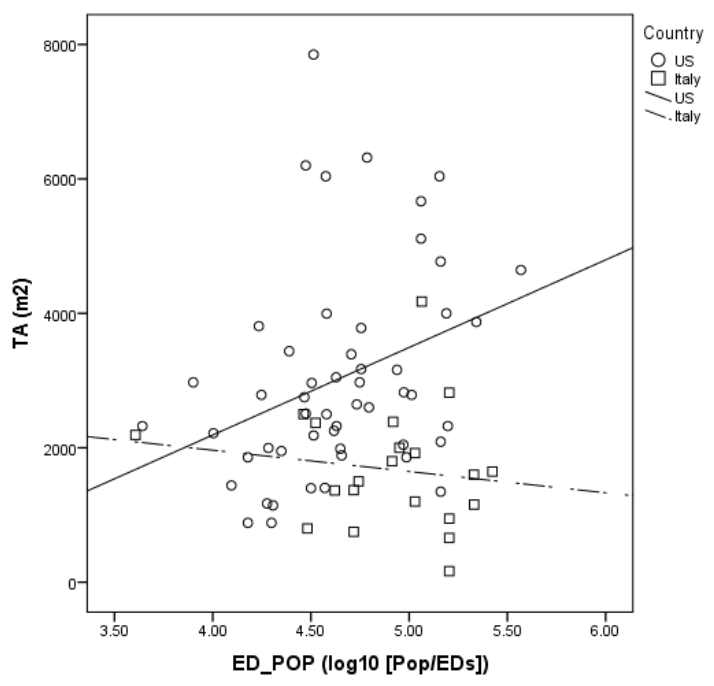

Figure 5: Deprived population against EDs floor area

\section{Space performance for vulnerable groups}

The relationship between the aging population (ED_APOP) and the total floor area (TA) has an incremental trend for the US EDs and is almost constant for the Italian case studies, see Figure 4. Figure 4 also shows that there is lack of long term provision for coping with access at the EDs for older patients, who represent a major proportion of Italian population. In Italy, over the last ten years the percentage of individuals aged 65 and over increased from $18.4 \%$ in 2001 to 20.3\% in 2011: an increase of no less than 1.8 million individuals in this age group (ISTAT, 2011). The contrast between the Italian and US approaches is also clear in the space provision for deprived population. Whilst the size of EDs in the US increases with population under the poverty line, the Italian ones are almost constant (see Figure 5). This can be read as one of the reasons why EDs in Italy are struggling with new types of 'poverty', such as the increase of illegal immigrants. In conclusion, the US EDs approach in estimating EDs total 
space is more accurate due to the adoption of an improved provision for information and methods (provided by centres such as CDC). Italian approach needs to be revised in order to capture the various components and variables that affect the design of EDs.

\section{Space performance for resilience and mass casualty events}

The indepth invetigation of the sample established that the case studies are exposed to technological, climatological, geophysical, hydrological and meteorological risks, and that each case study went through at least two different types of risks and some cases located in areas affected from 10 different disaster types, see Table 6. For example, whilst US case studies are highly exposed to climatological hazards, such as tropical storms and cyclones and local storms, Italian case studies are more likely to be affected by geophysical hazards: $100 \%$ of case study sample located in earthquake risk areas and 19\% located in areas with volcanic risks (see Table 6). For both the countries the proportion of EDs located in areas with technological risk is high: $20 \%$ of the US and $14 \%$ of Italian cases located in areas with risk of industrial accidents.

Disasters can be very different and can have different effects on buildings, causing different numbers and types of injuries. Resilience strategies usually take into account of available healthcare infrastructure in order to effectively manage mass casualties; however, this could be an ambitious target if EDs and healthcare facilities have limited space to accommodate extra patients when needed. Therefore, the design of such strategic and critical infrastructure should not be based on generic indications; instead it is required to be based on sufficiently accurate information that takes into account potential hazard implications. Researchers and engineers developed approaches, techniques, and tools to analyse and evaluate hazards, assess vulnerability and predict potential impact these could have on society and infrastructure. The application of these techniques and tools will provide information for designers to improve EDs, but most importantly will lead to the development of a new design process that is based on evidence as highlighted by Achour and Price (2011) and will eventually influence the current design practice and guidelines.

Table 4: List of disaster occurred in the areas where the EDs are sited 
Pascale, F, Achour, N, Price, A D F and Polverino, F (2014), Evaluation of factors and approaches affecting emergency department space planning, Facilities, 32(13/14), 761-785. DOI: http://dx.doi.org/10.1108/F-09$\underline{2012-0073}$

\begin{tabular}{|c|c|c|c|c|c|c|c|c|c|c|c|c|c|c|}
\hline \multirow[b]{2}{*}{ ID } & \multicolumn{4}{|c|}{ GEOPHYSICAL } & \multicolumn{3}{|c|}{ METEOROGICAL } & HYDR & OLOGICAL & CLIMATOLO & GICAL & & ECNOLOGICA & \\
\hline & Earthquake & Tsunami & Volcano & \begin{tabular}{|c|} 
Mass \\
Movement \\
(dry)
\end{tabular} & \begin{tabular}{|c} 
Tropical \\
Storm
\end{tabular} & $\begin{array}{l}\text { Tropical } \\
\text { cyclone }\end{array}$ & $\begin{array}{c}\text { Locall } \\
\text { Convective } \\
\text { storm }\end{array}$ & Flood & Landslide & $\begin{array}{c}\text { Extreme } \\
\text { temperature }\end{array}$ & $\begin{array}{l}\text { Wild } \\
\text { fire }\end{array}$ & \begin{tabular}{|c|} 
Industrial \\
Accident
\end{tabular} & $\begin{array}{c}\text { Miscellaneous } \\
\text { Accidents }\end{array}$ & $\begin{array}{l}\text { Transport } \\
\text { Accident }\end{array}$ \\
\hline US $/ 01$ & $\bar{x}$ & & & $x$ & & & $x$ & $\bar{x}$ & $x$ & $x$ & & & $x$ & $x$ \\
\hline US/02 & & & & $x$ & & & $x$ & $x$ & $x$ & & $x$ & & $x$ & $x$ \\
\hline US/03 & & & & & & & $x$ & $x$ & & & & & & $x$ \\
\hline US 104 & & & & & $x$ & $x$ & $x$ & $x$ & & $x$ & $x$ & & & $x$ \\
\hline US/05 & & & & $x$ & & & $x$ & $x$ & $x$ & & $x$ & & $\mathrm{x}$ & $x$ \\
\hline US/06 & & & & & $x$ & $x$ & $x$ & $x$ & & $x$ & $x$ & & & $x$ \\
\hline US/07 & & & & & $x$ & $\mathrm{x}$ & $x$ & $\mathrm{x}$ & & $x$ & & & & $\mathrm{x}$ \\
\hline US/08 & & & & & & & $x$ & $x$ & & $x$ & & & $x$ & $x$ \\
\hline US/09 & 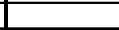 & & & & $x$ & $x$ & $x$ & $x$ & & $x$ & $x$ & $x$ & $x$ & $x$ \\
\hline US $/ 10$ & & & & 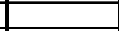 & $x$ & $x$ & $x$ & $x$ & & $x$ & $x$ & & & \\
\hline US/11 & & & & & & & $x$ & $x$ & & $x$ & & & $x$ & $x$ \\
\hline US/12 & & & & & & & $x$ & $x$ & & $x$ & 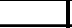 & & $x$ & $x$ \\
\hline US/13 & & & & & & & $x$ & $x$ & & $x$ & 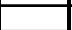 & & $x$ & $x$ \\
\hline US/14 & f & & & & & 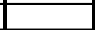 & $x$ & $x$ & & $x$ & & & $x$ & $x$ \\
\hline US/15 & & & & & & 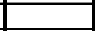 & $x$ & $x$ & & $x$ & & & $x$ & $x$ \\
\hline US/16 & $x$ & & $x$ & $x$ & & 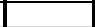 & $x$ & $x$ & & $x$ & $x$ & & $x$ & \\
\hline US /17 & & & & & & & $x$ & $x$ & & $x$ & & & & $x$ \\
\hline US/18 & $x$ & $x$ & & $x$ & & & $x$ & $x$ & $x$ & $x$ & 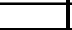 & & & \\
\hline \begin{tabular}{|l|l} 
US/19 \\
\end{tabular} & & & & & $x$ & $\mathrm{x}$ & $x$ & $x$ & & $x$ & - & & & $x$ \\
\hline US/20 & & & & & & & $x$ & $x$ & & $x$ & & & & \\
\hline US/21 & & & & & & 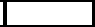 & $x$ & $x$ & & $x$ & 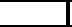 & & 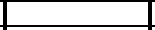 & 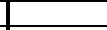 \\
\hline US/22 & & & & & & & $x$ & $x$ & & & 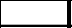 & & & \\
\hline US/23 & & & & & & & $x$ & $x$ & & $x$ & & & $x$ & $x$ \\
\hline US/24 & & & & & & 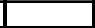 & $x$ & $x$ & & $x$ & $x$ & & $x$ & $x$ \\
\hline US $/ 25$ & & & & & & & $x$ & $x$ & & $x$ & $x$ & & $x$ & $x$ \\
\hline US $/ 26$ & & & & & $x$ & $x$ & $x$ & $x$ & & $x$ & & & $x$ & \\
\hline US $/ 27$ & & & & & & $x$ & $x$ & $x$ & & $x$ & 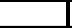 & $x$ & $x$ & $x$ \\
\hline US /28 & & & & & $x$ & $x$ & $x$ & $x$ & & $x$ & 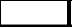 & & & \\
\hline US $/ 29$ & & & & & $x$ & $x$ & $x$ & $x$ & & $x$ & 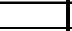 & & & \\
\hline \begin{tabular}{|l|l}
$U S / 30$ \\
\end{tabular} & & & & & $x$ & $x$ & $x$ & $x$ & & $x$ & 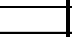 & & & \\
\hline \begin{tabular}{|l|l}
$U S / 31$ \\
\end{tabular} & & & & & $x$ & $x$ & $x$ & $x$ & & $x$ & & & & \\
\hline US $/ 32$ & & & & & & $x$ & $x$ & $x$ & & $x$ & & $x$ & $x$ & $x$ \\
\hline US $/ 33$ & & & & $x$ & $x$ & $x$ & $x$ & $x$ & & $x$ & & & & $x$ \\
\hline USI/34 & & & & & & & $x$ & $x$ & & $x$ & & $x$ & & \\
\hline US $/ 35$ & & & & & $x$ & $x$ & $x$ & $x$ & & $x$ & & $x$ & $x$ & $x$ \\
\hline \begin{tabular}{|l|l} 
US \\
\end{tabular} & & & & & $x$ & $x$ & $x$ & $x$ & & $x$ & $x$ & & & \\
\hline US $/ 37$ & & & & $x$ & & & $x$ & $x$ & $x$ & & $x$ & & $x$ & \\
\hline US $/ 38$ & & & & & - & 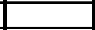 & $x$ & $x$ & & $x$ & & & $x$ & $x$ \\
\hline US $/ 39$ & & & & $x$ & & & $x$ & $x$ & & $x$ & & & $x$ & $x$ \\
\hline USI $/ 40$ & & & & $x$ & & & $x$ & $x$ & & $x$ & & & $x$ & $x$ \\
\hline US $/ 41$ & $x$ & $x$ & & $x$ & & & $x$ & $x$ & & $x$ & $x$ & & $x$ & $x$ \\
\hline US $/ 42$ & $x$ & & & & $x$ & $x$ & $x$ & $x$ & & $x$ & & $x$ & $x$ & $x$ \\
\hline US/43 & & & & & $x$ & $x$ & $x$ & $x$ & & $x$ & & $x$ & & \\
\hline US/44 & $x$ & $x$ & & $x$ & & & $x$ & $x$ & & $x$ & $x$ & $x$ & $x$ & $x$ \\
\hline US/45 & & & & & & & $x$ & $x$ & & $x$ & $x$ & & $x$ & $x$ \\
\hline USI/46 & & & & & & & $x$ & $x$ & & $x$ & & & $x$ & $x$ \\
\hline US/47 & $(-)$ & $(-)$ & $(-)$ & $(-)$ & $(-)$ & $(-)$ & $(-)$ & $(-)$ & $(-)$ & $(-)$ & $(-)$ & $(-)$ & $(-)$ & $(-)$ \\
\hline US $/ 48$ & $(-)$ & $(-)$ & $(-)$ & $(-)$ & $(-)$ & $(-)$ & $(-)$ & $(-)$ & $(-)$ & $(-)$ & $(-)$ & $(-)$ & $(-)$ & $(-)$ \\
\hline US $/ 49$ & $(-)$ & $(-)$ & $(-)$ & $(-)$ & $(-)$ & $(-)$ & $(-)$ & $(-)$ & $(-)$ & $(-)$ & $(-)$ & $(-)$ & $(-)$ & $(-)$ \\
\hline US $/ 50$ & & & & & & & $x$ & $x$ & & $x$ & & & $x$ & $x$ \\
\hline US $/ 51$ & & & & & $x$ & $x$ & $x$ & $x$ & & $x$ & & & & \\
\hline USI/52 & & & & & & & $x$ & $x$ & & $x$ & & & $x$ & $x$ \\
\hline US $/ 53$ & $x$ & $x$ & & $x$ & & & $x$ & $x$ & & $x$ & $x$ & $x$ & $x$ & $x$ \\
\hline US $/ 54$ & & & & & $x$ & $x$ & $x$ & $x$ & & & & $x$ & $x$ & $x$ \\
\hline US $/ 55$ & & & & & $x$ & $\mathrm{x}$ & $x$ & $x$ & & $x$ & & $x$ & & \\
\hline IT/01 & $x$ & & $x$ & $x$ & & & & $x$ & & $x$ & $x$ & & & $x$ \\
\hline $1 \mathrm{IT/02}$ & $x$ & & $x$ & $x$ & & & & $x$ & & $x$ & $x$ & & & $x$ \\
\hline IIT/03 & $x$ & & $x$ & $x$ & & & & $x$ & & $x$ & $x$ & & & $x$ \\
\hline $1 \mathrm{IT/04}$ & $x$ & & & & & & & & & $x$ & & $x$ & $x$ & $x$ \\
\hline $117 / 05$ & $x$ & & & & & & & & & $x$ & & $x$ & $x$ & $x$ \\
\hline $17 / 06$ & $x$ & & & $x$ & & & & $x$ & & $x$ & & & & $x$ \\
\hline $\mid T / 107$ & $x$ & & & & & & & $x$ & & $x$ & & & & \\
\hline $1 \mathrm{TT/08}$ & $x$ & & & & & & & $x$ & & $x$ & & & & $x$ \\
\hline IT/09 & $x$ & & & & & & & $x$ & & $x$ & & & & \\
\hline $\mathrm{IT} / 10$ & $x$ & & & & & & & $x$ & & $x$ & & & & \\
\hline $\mid T / 111$ & $x$ & & & & & & & $x$ & & $x$ & & & & \\
\hline $\mid \mathrm{IT/12}$ & $x$ & & & & & & & $x$ & & $x$ & & & & \\
\hline $\mathrm{IT/13}$ & $x$ & & & & & & & $x$ & & $x$ & & & & \\
\hline IT/14 & $x$ & & & & & & & $x$ & & $x$ & & & & \\
\hline IT/15 & $x$ & & & & & & & $x$ & & $x$ & & & & \\
\hline $\mathrm{IT/16}$ & $x$ & & & & & & & $x$ & & $x$ & & & & \\
\hline IT/17 & $x$ & & & & & & & $x$ & & $x$ & & & & \\
\hline IT/18 & $x$ & & & & & & & $x$ & & $x$ & & & & \\
\hline $\mid 1 T / 19$ & $x$ & & & & & & & $x$ & & $x$ & & & & \\
\hline IT/20 & $x$ & & $x$ & $x$ & & & & $x$ & & $x$ & $x$ & & & $x$ \\
\hline $\mid 1 T / 21$ & $x$ & & & & & & & & & $x$ & & $x$ & $x$ & $x$ \\
\hline
\end{tabular}




\section{Discussion}

\section{ED attendance variability}

Attendance variability is one of the major factors that need to be addressed for ED space planning. The assessment of different international guidelines demonstrated that ED space planning is based generally on the average number of annual accessions. Because of the variable nature of ED attendance, this approach does not meet ED needs; instead, it results in an underestimated total area which intensely affects its efficiency. Further research work is needed to investigate how to benefit more from operational approaches to estimate attendance variability in the ED design guidelines. This will provide a win-win situation as it will: (1) improve the impact of research findings; and (2) support decision making and design processes with scientific evidence that could be based on international experience.

The evaluation of guidelines developed in the US (ACEP), Australia (ACEM) and the UK (HBN22) highlight a significant gap between the HBN22 on one hand and the ACEP and ACEM on the other. The mean value of the total area, provided by the ACEP and ACEM guidelines is twice as big as the HBN22; whilst the maximum value is three times bigger. This could be due to the diversity of approaches to deal with ED patients in the US, Australia and the UK. ACEP and ACEM service models are based on the Triage model whilst the HBN22 is based on the See and Treat model, developed from the Lean principles. The implementation of Lean principles in the UK indicates that the healthcare system is driven by management processes rather than the development of physical infrastructure. This is a good strategy to control the expenditure and healthcare quality, but it can compromise resilience in the case of mass casualties.

Space performance was assessed by analysing the trend of ED total area in relation to attendance, compared with international guidelines, and to cities' populations. The findings demonstrate that the US and Italian EDs total area and attendance have a rising trend. However, the US case studies, on average, are twice as large as the Italian ones, and the latter cases studies are closer to the UK model. In addition, while the area of EDs in the US increases with the rise of potential patients, the size of Italian ones decreases, which leads to the conclusion that the Italian case studies were designed according to old design approaches and thus are more susceptible to face problems in coping with high demands.

\section{Vulnerable groups}

With the current trend of social and environmental change, vulnerable groups are some of the most crucial factors affecting ED overcrowding. For this reason, social specifications (e.g. elderly, children and deprived people) should be considered as incremental factors in space planning. The analysis of international guidelines lead to conclude that even when supportive calculation methods are available, and that guidelines recognise the significant effect vulnerable groups have on EDs, they fall short in providing measurable indicators to ensure these groups are well considered in space planning. This should be taken into account in future research in order to define an effective operative approach for improved integration. 
Case studies space performance, related to social issues, was assessed by analysing the relationship between the total area and ageing and deprived populations. For both countries (Italy and the US), the total area has a proportional rising trend with the ageing population; however, the US EDs have a steeper trend than the Italian case studies. This indicates that in Italy there is a lack of long term provision for coping with elderly access. In addition, the size of the US EDs increased with population under the poverty line, whilst the size of Italian ones is almost constant. This could be explained by the quality of data used by these cohorts, which is available in the US.

\section{Mass casualty events}

The increasing number of risks emphasised the need for resilient EDs, capable of accommodating and dealing with the potential, and associated, mass casualties. The analysis of the guidelines demonstrates that in the last 10 years important pilot studies have been developed to improve performance of EDs in special circumstances, such as Project ER One; the developed concepts and design features are not integrated into the international guidelines. Moreover, there is inconsistency between the recognition of disaster management and ED design in international guidelines. Although some research projects have been developed, the current economic climate requires more cost-effective solutions in approach to facilitate the integration between hazards, resilience, ED space planning and budget restraints.

Most of the case studies are located in disaster prone areas, which implies that these facilities are at risk of being affected by one or more hazards. Findings suggest that all these facilities are based in areas of high technological risks; however, in terms of natural hazards, the historical records suggest that the US case studies have been significantly affected by climatological hazards whilst Italian case studies were affected by geophysical hazards. In most of the cases, these events have the potential to evolve MCE. Since EDs have a high risk of being affected by disasters, generic indications do not meet the the complexity of the problem. In the view to improve the overall capacity of the healthcare system within an acceptable radius from a potential disaster area, there is the need to identify the facility mission and role in normal and contingency operations of each available ED, and to define the needed surge capacity in accord with their role. ED design process needs to benefit from modern techniques and tools of risk assessment and vulnerability evaluation in order to ensure resilience. This will benchmark the current design practice and improve design guidelines.

\section{Conclusion and future work}

Emergency departments perform a strategic role in disasters; however, daily operational issues such as overcrowding are increasing concerns about their ability to cope with a sudden surge in demand. There is a requirement for them to be designed to cope with challenges related to daily and special surge, and fundamental factors affecting the performance of EDs need to be taken into account in space planning. These are ED attendance variability; vulnerable groups and mass casualty events. The approach, proposed in international 
guidelines for EDs space planning is based on attendance averages, which underestimates space needs and fails to address the entire services provision. Design guidelines recognise the crucial role EDs play in disaster management and that they are heavily affected by vulnerable groups in their daily operation. However, there are no indications as to how to consider them in space planning. For these reasons, many EDs do not meet the effectiveness, efficiency and resilience needs.

The US EDs were designed according to operational approaches; this put them in a better position to meet with a sudden increase in demand; whilst Italian EDs were designed according to old design approaches which made them vulnerable to fail to meet with a sudden surge in demand. To improve the performance of the EDs throughout the whole service provision, there is a need to adopt cost-effective design strategies, which take in into account factors relating to daily functions and special circumstances. ED attendance variability, vulnerable groups and MCE must be considered fully and a generic model for space planning is unsustainable. This study shows that research can provide a valuable contribution to improve ED design and to improve design processes and guidelines. The study evaluated ED space planning design using trends which will be taken further to develop a prediction model that will lead to a more resilient design approach. This will provide design guidelines with relevant indicators to integrate attendance variability, vulnerable groups and mass casualty events and ultimately will influence design practice.

\section{References}

AARP (2006), "AARP Offers Tips to Help Older Americans Prepare for Emergencies ", available at: http://www.aarp.org/about-aarp/press-center/info2006/preparing_for_emergencies.html (accessed 02 May 2012).

ACEM (2007), Guidelines on Emergency Department Design. http://www.acem.org.au/media/policies_and_guidelines/G15_ED_Design.pdf:

Australian College for Emergency Medicine

ACEP (2006), "Crowding", Annals of Emergency Medicine, Vol. 47, No., pp. 585.

ACEP (2011), "Health Care System Surge Capacity Recognition, Preparedness, and Response", available at: http://www.acep.org/content.aspx?id=29506 (accessed 19 December 2011.

Achour, N. \& Price, A. D. F. (2011), "Healthcare resilience to natural hazards: an achievable target (Guest Editorial)", International Journal of Disaster Resilience in the Built Environment (IJDRBE), Vol. 2, No. 3.

Adirim, T. (2009), "Protecting Children During Disasters: The Federal View", Clinical Pediatric Emergency Medicine, Vol. 10, No. 3, pp. 164-172.

Adnkronos Salute (2011), "Health care: 30 million Italians a year to the emergency room, 75\% for biblical waiting time", available at: http://www.adnkronos.com/IGN/Daily_Life/Benessere/Sanita-30-mln-italiani-lannoal-pronto-soccorso-per-75-attese-bibliche_689050476.html (accessed 01 May 2011).

Althaus, F., Paroz, S., Hugli, O., Ghali, W. A., Daeppen, J.-B., Peytremann-Bridevaux, I. \& Bodenmann, P. (2011), "Effectiveness of Interventions Targeting Frequent Users of Emergency Departments: A Systematic Review", Annals of Emergency Medicine, Vol. 58, No. 1, pp. 41-52. 
Aminzadeh, F. \& Dalziel, W. B. (2002), "Older adults in the emergency department: A systematic review of patterns of use, adverse outcomes, and effectiveness of interventions", Annals of Emergency Medicine, Vol. 39, No. 238-247.

Arkun, A., Briggs, W. M., Patel, S., Datillo, P. A., Bove, J. \& Birkhahn, R. H. (2010), "Emergency department crowding: factors influencing flow", West J Emerg Med, Vol. 11 , No. 1, pp. 10-5.

Berry, R. (2009), Designed to survive. Medical Construction \& Design.

Bethel, J. W., Foreman, A. N. \& Burke, S. C. (2011), "Disaster Preparedness Among Medically Vulnerable Populations", American Journal of Preventive Medicine, Vol. $139-143$, No. 40, pp. 2.

Bianco, A., Pileggi, C. \& Angelillo, I. F. (2003), "Non-urgent visits to a hospital emergency department in Italy", Public Health, Vol. 117, No., pp. 250-255.

Booth, R. \& McCurryo, J. (2011), "Japanese earthquake takes heavy toll on ageing population", available at: http://www.guardian.co.uk/world/2011/mar/17/japaneseearthquake-toll-ageing-population-deaths (accessed 02 May 2012).

Burke, R. V., Iverson, E., Goodhue, C. J., Neches, R. \& Upperman, J. S. (2010), "Disaster and mass casualty events in the pediatric population", Seminars in Pediatric Surgery, Vol. 19, No. 4, pp. 265-270.

Carmel, S., Anson, O. \& Levin, M. (1990), "Emergency department utilization: A comparative analysis of older-adults, old and old-old patients", Aging (Milan), Vol. 2, No. 4, pp. 387-393.

CFEC (2007), "Improving the efficiency of hospital-based emergency care", In: COMMITTEE ON THE FUTURE OF EMERGENCY CARE IN THE UNITED STATES HEALTH SYSTEM (ed.) Hospital-Based Emergency Care: At the Breaking Point, The National Academies Press, Washington, D.C., 129-164.

Cooke, M., Fisher, J., Dale, J., McLeod, E., Szczepura, A. \& Walley, P. (2004), Reducing Attendances and Waits in Emergency Departments A systematic review of present innovations, The National Co-ordinating Centre for NHS Service Delivery and Organisation R \& D (NCCSDO), London.

CPEM (2004), "Overcrowding Crisis in Our Nation's Emergency Departments: Is Our Safety Net Unraveling?", Pediatrics, Vol. 114, No. 3, pp. 878-888.

Crane, J. \& Noon, C. (2011), The Definitive Guide to Emergency Department Operational Improvement. (2011). CRC Press, New York, NY.

CRED (2011a), "“Disaster Data: A Balanced Perspective”. Issue No. 24", Bruxelles, CRED, available at: http://cred.be/sites/default/files/CredCrunch24.pdf (accessed 12 September 2011).

CRED (2011b), "“Disaster Data: A Balanced Perspective”. Issue No. 26", Bruxelles, CRED, available at: http://www.cred.be/sites/default/files/CredCrunch26.pdf (accessed 23 January 2012).

DH (2005), HBN 22 Accident and emergency facilities for adults and children, The Stationery Office, Norwich, UK.

Dove, A. F. \& Dave, S. H. (1986), "Elderly patients in the accident department and their problems", British Medical Journal, Vol. 292, No., pp. 807-809.

Exadaktylos, A., Evangelopoulos, D., Wullschleger, M., Burki, L. \& Zimmermann, H. (2008), "Strategic emergency department design: An approach to capacity planning in healthcare provision in overcrowded emergency rooms", Journal of Trauma Management \& Outcomes, Vol. 2, No. 1, pp. 11.

Fatovich, D. M. (2002), "Emergency medicine", British Medical Journal, Vol. 324, No. 7343, pp. 958-962. 
Fernandez, L. S., Byard, D., Lin, C., Benson, S. \& Barbera, J. A. (2002), "Frail Elderly as Disaster Victims: Emergency Management Strategies", Prehospital and Disaster Medicine, Vol. 17, No. 2, pp. 67-74.

Galbraith, A. A., Semura, J., McAninch-Dake, B., Anderson, N. \& Christakis, D. A. (2004), "Emergency Department Use and Perceived Delay in Accessing Illness Care Among Children With Medicaid", Ambulatory Pediatrics, Vol. 4, No. 6, pp. 509-513.

Gray, B. H. \& Hebert, K. (2007), "Hospitals in Hurricane Katrina: Challenges Facing Custodial Institutions in a Disaster", Journal of Health Care for the Poor and Underserved, Vol. 18, No. 2, pp. 283-98.

GRMMI (2009), M6.3 L'Aquila, Italy. Earthquake Field Investigation Report. http://www.grmcat.com/images/Italy-EQ-Report.pdf: Global Risk Miyamoto and Myamoto International.

Gruneir, A., Silver, M. J. \& Rochon, P. A. (2011), "Review: Emergency Department Use by Older Adults: A Literature Review on Trends, Appropriateness, and Consequences of Unmet Health Care Needs", Medical Care Research and Review, Vol. 68, No. 2, pp. 131-155.

Halpern, P., Tsai, M.-C., Arnold, J. L., Stok, E. \& Ersoy, G. (2003), "Mass-Casualty, Terrorist Bombings: Implications for Emergency Department and Hospital Emergency Response (Part II)", Prehospital and Disaster Medicine, Vol. 18, No. Special Issue 03, pp. 235-241.

Hayward, C. (2006), SpaceMedGuide - A Space Planning Guide for Healthcare Facilities Space Med, USA.

Hoot, N. R., Aronsky, D, (2008), "Systematic Review of Emergency Department Crowding: Causes, Effects, and Solutions", Ann Emerg Med, Vol. 52, No. 2, pp. 126-36.e1.

HSCIC (2012a), "Accident and Emergency Attendances in England (Experimental statistics) 2010-11 data", available at: http://www.ic.nhs.uk/pubs/aandeattendance1011 (accessed 02 May 2012).

HSCIC (2012b), Accident and Emergency Attendances in England (Experimental Statistics), 2010-11.

http://www.ic.nhs.uk/webfiles/publications/004_Hospital_Care/HES/AandE_attendan ces_Eng_2010-11/AandE_Emergency_Attend_Eng_2010_11_report.pdf: The Health and Social Care Information Centre.

Huddy, J. (2002), Emergency Department Design: A practical Guide to Planning for the Future, American College of Emergency Physicians, Dallas, Texas, USA.

Huddy, J., McKay, J, I, (1996), "The top 25 problems to avoid when planning your new emergency department", Journal of emergency nursing, Vol. 22, No. 4, pp. 296-301.

IOM "Medical Surge Capacity: Workshop Summary", in: INSTITUTE OF MEDICINE OF THE NATIONAL ACADEMIES (IOM), ed., The National Academies Press.

ISTAT (2011), "Demographic Indicators", available at: http://www3.istat.it/salastampa/comunicati/in_calendario/inddemo/20110124_00/testo integrale20110124.pdf (accessed 01 May 2012).

Johnson, B. R. \& Anthony, J. (2004), "Mixed Methods Research: A Research Paradigm Whose Time Has Come", Educational Researcher, Vol. 33, No. 7, pp. 14-26.

Johnson, R. B., Onwuegbuzie, A. J. \& Turner, L. A. (2007), "Toward a Definition of Mixed Methods Research", Journal of Mixed Methods Research, Vol. 1, No. 2, pp. 112-133.

Jones, D., Mitchell, A., Ben-Tovim, D., Fillingham, D., Makin, C., Silvester, K., Brunt, D. \& Glenday, I. (2006), Lean thinking for the NHS, NHS Confederation, London. 
Jones, S. S., Thomas, A., Evans, R. S., Welch, S. J., Haug, P. J. \& Snow, G. L. (2008), "Forecasting Daily Patient Volumes in the Emergency Department", Academic Emergency Medicine, Vol. 15, No. 2, pp. 159-170.

Magid, D. J., Sullivan, A. F., Cleary, P. D., Rao, S. R., Grdon, J. A., Kaushal, R., Guadagnoli, E., Camargo, C. A. \& Blumenthal, D. J. (2009), "The Safety of Emergency Care Systems: Results of a Survey of Clinicians in 65 US Emergency Departments", Annals of Emergency Medicine, Vol. 53, No. 6, pp. 715-723.

Malone, R. E. (1995), "Heavy users of emergency services: Social construction of a policy problem", Social Science \&amp; Medicine, Vol. 40, No. 4, pp. 469-477.

McCarthy, M. L., Aronsky, D. \& Kelen, G. D. (2006), "The Measurement of Daily Surge and Its Relevance to Disaster Preparedness", Academic Emergency Medicine, Vol. 13, No. 11, pp. 1138-41.

Newton, M. F., Keirns, C. C., Cunningham, C. \& al., e. (2008), "Uninsured Adults Presenting to US Emergency Departments: Assumptions vs Data", The Journal of the American Medical Association, Vol. 300, No. 16, pp. 1914-1924.

Niska, R., Bhuiya, F., Xu, J. \& Division of Health Care Statistics (2010), "National Hospital Ambulatory Medical Care Survey: 2007 Emergency Department Summary", Hyattsville, MD, National Center for Health Statistics, available at: http://www.cdc.gov/nchs/data/ahcd/nhamcs_emergency/nhamcsed2008.pdf (accessed 01 May 2012).

Niska, R. W. \& Shimizu, I. M. (2011), "National Hospital Ambulatory Medical Care Survey: 2008 Emergency Department Summary Tables", Hyattsville, MD, National Center for Health Statistics, available at: http://www.cdc.gov/nchs/data/ahcd/nhamcs_emergency/nhamcsed2008.pdf (accessed 01 May 2012).

Palleschi, L., Maida, R. \& Crerqua, G. (2003), "The elderly patient in the emergency department: a reality 'always more' current, critical to the efficiency and effectiveness of the entire health system. What possible solutions?", available at: http://www.simeu.it/convegni/2003/Naz2003/AnzianiEDPalleschiCerquaSGiovanni.pdf (accessed 01 May 2012).

Saluter (2012), "Earthquake Info: care, advanced medical points, hospitals, care facilities and territorial care", available at: http://www.saluter.it/news/regione/terremoto-lasituazione-di-assistenza-punti-medici-avanzati-ospedali-alle-ore-18.30 (accessed 04 June 2012).

Schneider, S. M., Gallery, M. E., Schafermeyer, R. \& Zwemer, F. L. (2003), "Emergency department crowding: A point in time", Annals of Emergency Medicine, Vol. 42, No. 2, pp. 167-172.

SEPHO (2010), "Vulnerable groups", available at: http://www.sepho.org.uk/vulnerablegroups.aspx (accessed 31 May 2012).

Sills, M. R., Fairclough, D., Ranade, D. \& Kahn, M. G. (2011), "Emergency Department Crowding Is Associated With Decreased Quality of Care for Children With Acute Asthma", Annals of Emergency Medicine, Vol. 57, No. 3, pp. 191-200.e7.

SIMEU (2005), Structural, technological, organizational and staff standard for Emergency Departments, Tipolito Stear, Ravenna.

SIMEU (2007), "SIMEU plan for the construction of Territory- Hospital Integrated System for Emergency-Urgency", available at: http://www.simeu.it/emiliaromagna/documenti/Programma_SIMEU_per_la_MU.pdf (accessed 04 April 2011). 
Smith, M., Feied, C., Pietrzak, M. P., Pickard, J., Hawkins, R. \& Vincent, D. (2003), ER One Technical Reports, Phase I \& II., ER One Institute, Washington, DC.

Stratton, S. J. \& Tyler, R. D. (2006), "Characteristics of Medical Surge Capacity Demand for Sudden-impact Disasters", ACADEMIC EMERGENCY MEDICINE, Vol. 13, No., pp. 1193-1197.

Sun, B. C., Burstin, H. R. \& Brennan, T. A. (2003), "Predictors and Outcomes of Frequent Emergency Department Users", Academic Emergency Medicine, Vol. 10, No. 4, pp. 320-328.

Tuohy, R. \& Stephens, C. (2012), "Older adults' narratives about a flood disaster: Resilience, coherence, and personal identity", Journal of Aging Studies, Vol. 26, No. 1, pp. 26-34.

Van Zandt, S. E., Sloand, E. \& Wilkins, A. (2008), "Caring for Vulnerable Populations: Role of Academic Nurse - Managed Health Centers in Educating Nurse Practitioners", The Journal for Nurse Practitioners, Vol. 4, No. 2, pp. 126-131.

Welch, S. J. \& Park, O. (2009), Quality Matters: Solutions for a Safe and Efficient Emergency Department, Joint Commission Resources Oak Park, IL.

WHO (2007), Mass Casualty Management systems: Strategies and Guidelines for building health sector capacity. Geneva: World Health Organization.

Zilm, F. (2004), "Estimating Emergency Service Treatment Bed Needs", J Ambul Care Manage, Vol. 27, No. 3, pp. 215-223.

Zilm, F. (2007), "A new era of emergency care: planning and design consideration", Journal of Ambulatory Care Management, Vol. 30, No. 3, pp. 259-63.

Zilm, F. (2008), "Integrating Disaster Preparedness and Surge Capacity in Emergency Facilities Planning ", J Ambul Care Manage, Vol. 31, No. 4, pp. 377-385.

Zilm, F., Berry, R., Pietrzak, M. P. \& Peratore, A. (2008), "Integrating Disaster Preperedness and Surge Capacity in Emergency Facility Planning", The Journal of Ambulatory Care Management, Vol. 31, No. 4, pp. 377-385.

Zilm, F., Crane, J. \& Roche, K. T. (2010), "New Directions in Emergency Service and Operations and Planning", J Ambul Care Manage, Vol. 33, No. 4, pp. 296-306. 